\title{
Plant epigenetics
}

\section{ANALYSIS OF EPIGENOMIC AND EPIPLASTOME VARIABILITY IN THE HAPLOID AND DIHAPLOID SUGAR BEET (Beta vulgaris L.) PLANTS}

\section{S.I. MALETSKII, S.S. YUDANOVA, E.I. MALETSKAYA}

Institute of Cytology and Genetics of SD of Russian Academy of Science, Federal Agency of Scientific Organizations, 10, pr. Lavrentieva, Novosibirsk, 630090 Russia, e-mail stas@bionet.nsc.ru Acknowledgements:

Supported by a budget project of Institute of Cytology and Genetics of SD of RAS

Received July 28, 2014

\section{Abstract}

Reproduction of cells, individuals, populations is a principal concept of biology. This process is characterized by two properties: heredity and variation. The concept of inheritance indicates the identity of the parents and the offspring's; the concept of variability indicates the incompleteness of this identity. There is a direct proportional relationship between the genome level ploidy, the cytoplasm volume and the cell size (nuclear-plasma ratio). Variation of chromosome or chromatid numbers in the cell nuclei determines the epigenomic variability and variation of intracellular organelle numbers in the cell (for example chloroplasts) determines epiplastome variability in plants. Relationship of the chloroplast number in stomata guard cells and nucleus ploidy level in sugar beet is well known that permit to compare an epiplastome variability in plants and different ploidy of genomes. Chloroplast number in the cells varies, partly due to the asymmetric organelle distribution during cytokinesis. However the epiplastomic variability is related not only with a random organelle distribution during cytokinesis, but also with a genome number variation per cell nucleus (epigenomic variability). An endohaploidy, i.e. an appearance of haploid cells in cell population, is one of the variant of epigenetic variability display. Sugar beet may form the haploid seeds spontaneously both by biparental and uniparental reproduction. In the work the diploid (control, generation $\mathrm{A}_{0}$ ), dihaploid and haploid (generation $A_{1}$ ) seed progeny were used. Dihaploids and haploids were obtained by the parthenogenetic reproduction mode (pollen less condition). In the paper we considered a variability of chloroplast number in stomata guard cells and integral tissue characteristics which are compared with harmonious proportions (Fibonacci number, golden ratio). It was studied following parameters: a) a chloroplast number in stomata the guard cells; b) a plastotype number in the epidermal tissue. And it was determined the average value of chloroplast $(\mathrm{M})$ and plastotypes $(\mathrm{Pt}) \mathrm{num}$ ber in stomata guard cells of haploid, diploid and dihaploid plants. On the base of obtained data the ratios of epigenetic stability (D-ratio) in haploid, diploid and dihaploid (control) sugar beet plants were estimated. D is logarithmic ratio of the chloroplast number to plastotypes and indicates the physiological and epiplastome stability of cell populations. It was shown the differences between the experiment simples: D-ratio in dihaploids is always above than one in the haploids. It was established for the first time that integral tissue characteristic (D-ratio) corresponds to harmonious proportions (bio-logical invariants), i.e. Fibonacci numbers (golden ratio). In diploids and dihaploids this ratio corresponds to the first terms of the harmonious series (from first to fifth), in haploids D-ratio corresponds to eighth and higher terms of the harmonious sequence.

Keywords: apozygoty, haploids, dihaploids, variability, harmonious proportions, fractals, endopolyploidy, epigenetics.

Reproduction of cells, individuals, populations is a principal concept of biology. This process is characterized by two properties: heredity and variation. The concept of inheritance indicates the identity of the parents and the offspring's [1], and the concept of variation indicates the incompleteness of this identity. There are two distinct types of variations, the inherited genetic variations derived from genome mutations and epimitations, and the non-inherited paratypical modifications due to inner or outer factors influencing biogenesis. At cell level the heredity means the competence of cell components to provide 
structural and functional similarity (symmetry) in the next offspring due to reproduction, i.e. self-reduplication of DNA, chromatids, chromosomes, and chloroplasts and mitochondria organelles. As the self-duplication is completed, the nucleus and chromosomes divide by means of the division spindle (cariokinesis, mitosis) and cytoplasmic membrane septum formation followed by separation of daughter cells (cytokinesis). The daughter nuclei produced in cariokinesis are usually the copies of the parent cell while exact distribution of organelles between daughter cells is impossible.

In mitosis intercellular variation does not occur, and therefore in the Mendelian inheritance paradigm the daughter cells are considered parent clones [2]. Random nucleotide substitutions in the DNA molecules (gene mutation) and reciprocal or nonreciprocal exchanges (recombination) of homologous chromosomes during meiosis are usually deemed the main sources of intercellular variations in the tissues. These basic assumptions form the basis for a genocentric paradigm (GCP) of inheritance and variability and associate trait variation and the chromosome structure, but do not apply to all groups of features [3].

There are discrete (qualitative) and continuous (quantitative) traits. The discrete traits are alternative and their variation is usually caused by mutations in genes of the nucleus or protoplasm, while the variation of the continuous traits (i.e., number of flowers, seeds and fruits on plants, etc.) is not directly linked to the gene activity being influenced by outer signaling derived from growth conditions, density of planting in phytocenosis, etc.). A clear description of the inheritance of continual traits within GCP is very difficult, therefore, their polygenic determination is declared.

Epigenetic paradigm (EGP) does not bind cellular and individual variations solely to changes in the nucleotide sequences of DNA, chromosome structure and recombination of chromosomes in meiosis [3, 4]. Variability in cell populations may occur due to the volatility in the chromosome number (mixoploidy) or DNA amount in the nucleus. Mixoploidy in plants was reported in 1910, and in 1935 this phenomenon was found in members of the family Chenopodiaceae to which the beet plants belong.

Another mechanism of intracellular variation in somatic cells is the variability in the number of chromatids in chromosomes when along with monochromatid chromosomes duple and quadruple chromosomes are also found. The variations of the DNA amount, the number of chromosomes or chromatids are very common mechanisms of epigenomic and epigenetic variation in plants [5-7]. There is a direct proportional relationship between the genome level ploidy, the cytoplasm volume and the cell size (nuclear-plasma ratio). A volatility of DNA level in somatic cells is confirmed cytometrically [8-14].

Epidermal cell variability in organelle number is partially related to endoploidy due to spontaneous changes in chromosome ot chromatid number in the diploid cell nucleus proportionally to the number of endomitosis [6, 15]. Endopolyploidy does not affect the nucleotide sequences in DNA and chromosome structure and occurs during DNA replication in the cell nucleus not followed by its division. These processes lead to volatility in the DNA levels in the cell populations which is the main source of cell and tissue variation in plants [6-13]. Note, the first researchers, the same as modern scientists, confirmed high prevalence of this phenomenon in the family Chenopodiaceae [10-14].

Endohaploidy (the appearance of cells with single set of chromosomes) is a mechanism of epigenomic variation in somatic cells. Haploidy is experimentally effective for genome homozygotization. Sugar beet may form the haploid seeds spontaneously both by biparental and uniparental reproduction with 
the haploid seedling frequency of $10^{-4}-10^{-6}$ and $0.5 \times 10^{1}$, respectively $[16,17]$.

According to EGP a special group of traits, the fractal or geometric ones, inherent in cell or plant as a whole can be distinguished. These include, in particular, the structure of the vascular system (xylem and phloem), the root system [18], and embryonic and tissue characteristics. Mathematically, the discrete, continuous and fractal characteristics can be clearly distinguished by a geometric dimension (D). In the discrete and continuous traits D is expressed in whole numbers (one-, two-, or three-dimensional features), while in the fractal traits the fractional dimension is characteristic [18].

Variation in chromatid and chromosome number affects directly their distribution in meiosis, and, therefore, offspring splitting on traits [3, 17]. Moreover, an increased DNA content in nucleus can influence the cell size and number of organelles (chloroplasts) in the cytoplasm [19]. Chloroplasts possess their own genome. This plastid number per cell in plant tissues varies from several ones to hundreds of chloroplasts. Prior to cell division, the self-replication of chloroplasts occurs, and daughter cells are assumed to posses the same organelle number as the parent cell. In case of exact splitting in a series of cell offspring, chloroplast number in each plant cell must be the same as in initial zygotic cell, however, but it has never been. Plastid distribution in cytokinesis is asymmetric. Epiplastom variation is due not only to random distribution of organelles in cytokinesis but also to DNA amount and genome number per cell nucleus (epigenomic variation), since the nucleus size, cytoplasm volume, the number of organelles are in a direct proportional relationship.

The relationship between chloroplast number, ploidy and cell size is well known in sugar beet plants. In the studies focused on the production of polyploids an indirect convenient procedure for plant grouping according to ploidy has been disclosed. Thus, in stomata guardian cell of triploids and tetraploids there were reliably more chloroplast (from 17 to 22 and from 22 to 28 , respectively) compared to diploids (from 12 to 16). This finding permits to compare epiplastome variation in haploids, dihaploids, tripoids, tetraploids, etc.

In this article we compared integral tissue parameters (i.e. the ratio of its variation to an average number of organelles) and showed for the first time that these are in a concordance to harmonic proportions (biological invariants) denoted as $\rho$-numbers or the Fibonacci numbers, which, in turn, correspond to the golden $\rho$-proportion.

So our study was focused on experimental estimation of chloroplast number variability in stomata guard cells in haploid, dihaploid and diploid sugar beet plants.

Technique. The seeds of sugar beet (Beta vulgaris L.) dioloid male sterile (MS) hybrids Roksana, Lenora, Iris $\left(\mathrm{F}_{1}\right.$, or $\left.\mathrm{A}_{0}\right)$, and their apozigotic dihaploid and haploid seed progeny $\left(\mathrm{A}_{1}\right)$ were used. The study was carried out from 2009 to 2012 in field condition (Novosibirsk). To produce apozygotic seed progeny (memo: apozygoty means embtyo parthenogenesis from unfertilized cells of the embryo sac) the roots were planted on an isolated plot, and in each plant at flowering the phenotype of anthers and pollen grains was recorded. The plants of MSII phenotype (semi-fertile) were eliminated [19] and the MS0 (complete pollen sterility) and the MSI (pollen semi-sterility) individuals were remained for apozigotic seed reproduction.

The seed samples from the progeny $\left(\mathrm{A}_{1}\right)$ of each MS-hybride set after 2 day rinsing in tap water were incubated in thermostat at $25{ }^{\circ} \mathrm{C}$, and 2 day after the germination the seedlings were separated morphobiologically as haploids and dihaploids (in vivo production of haploids) [16, 20]. Then seedlings were grown in individual pots at a climatic chamber Biotron 4 (Russai) under controlled 
humidity, temperature and lightening for first 100 days of life. Further, haploids and dihaploids were undergone vernalization at $\mathrm{t}=4{ }^{\circ} \mathrm{C}$ and planted in a field.

Chloroplasts were counted in epidermal cells of 1 year leaves. Selected leaves were average in size. Epiderma was removed from the underside leaf part. Chloroplasts were stained with $\mathrm{AgNO}_{3}$ and counted in each of 50 epidermal cells. The number of plastotypes $(\mathrm{Pt})$ was estimated in the tissue, and an average chloroplast number in cells (M) was calculated. Epidermal tissue was characterized using $\mathrm{M}$ and $\mathrm{Pt}$ parameters as $\mathrm{M}: \mathrm{Pt}$. An average number of cell organelles and number of plastotypes in the cell population a related as $\mathrm{M}=\mathrm{Pt}^{\mathrm{D}}$. Thus, $\mathrm{D}$ (fractional dimension) being the integral parameter of epidermal tissue [18] was calculated as $\mathrm{D}=\ln \mathrm{M} / \mathrm{ln} \mathrm{Pt}$.

Data were processed using common methods of variation statistics [21]. For each plant, we found $\sigma^{2}$, the arithmetic mean of organelle number per cell (in 50 cells for each leaf) and $M \pm m$, also weighted average $M_{\mathrm{w}}$ in a sample was calculate and $C V$ was determined as

$$
C V=\frac{100 \sigma}{M} \times 100 \%
$$

Besides, in leaf samples of each specimen an average number of plastotypes with the error of mean $(\mathrm{Pt} \pm m)$ were estimated. The coefficient of linear correlation $(r)$ was calculated according to the formula:

$$
r=\frac{\sum a_{x} a_{y}}{n \sigma_{x} \sigma_{y}},
$$

with $a_{X}$ and $a_{y}$ as variance deviations from arithmetic mean, $n$ as sample size, and $\sigma$ as standard deviation.

Using goodness of fit test $(G)$ multiple-tables were analyzed statistically comparing discrete distributions with null hypothesis. $G$ was calculated as

$$
G=2\left(\sum_{i} f_{i} \ln \frac{f_{i}}{f_{i}^{\prime}}\right)=2 \sum_{i} f_{i}\left(\ln f_{i}-\ln f_{i}^{\prime}\right),
$$

with $f_{i}$ и $f_{i}^{\prime}$ as empirical and theoretical frequency of discrete distributions of specific trait [21].

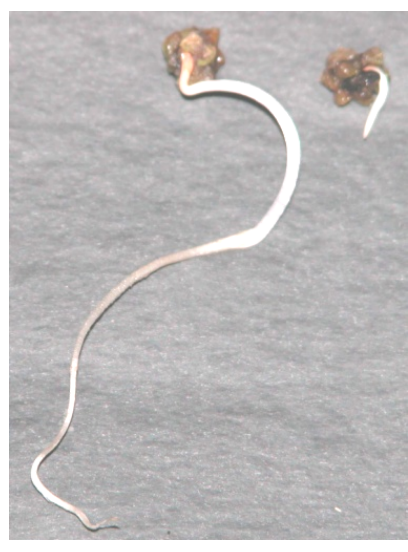

Fig. 1. Diploid (left) and haploid (right) seedlings of sugar beet (Beta vulgaris L.).

Results. A multividual variation is inherent in sugar beet plant, that is the flowers of the main shoot and side-shoots can differ in the anther phenotype [22]. There are three distinct phenotypes according to anthers and pollen: i) complete pollen sterility due to defective anthers and pollen (MS0); ii) pollen semi-sterility when uninucleate pollen grains are unable to form pollen tube (MSI); iii) semifertility when pollen grains are partly viable (MSII). The seeds were obtained from MS0 and MSI plants.

Apozygotic seed progenies are usually diploids (dihaploids) as derived from endotetraploid cells of archesporium. In addition to dihaploids, some apozygotic seeds were haploids [16, 17]. Haploid seedlings are 4-fold shorter and smaller in diameter compared to dihaploid sibs (Fig. 1).

Chloroplast number in an individual epidermal cell we have designated as plastotype $(\mathrm{Pt})$. There were several plastotypes different in the chloroplast (Fig. 2). In contrast to chloroplast number the number of plastotype is an integral trait inherent in a discrete leaf (a discrete plant). The $\mathrm{M}: \mathrm{Pt}$ ratio changes stochastically during plant ohtogenesis in accordance to 


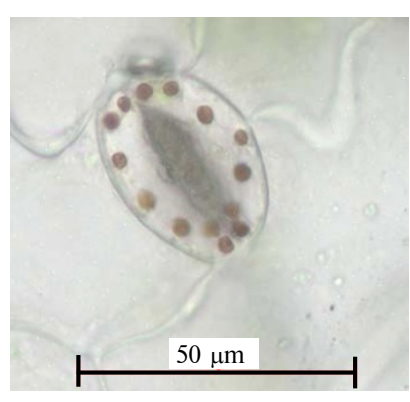

Fig. 2. Chloroplasts in the stomata guardian cells in leaves (epidermal tissue of sugar beet Beta vulgaris L.)

Earlier we have shown this proportion not to be the same in hybrid and inbred plants [16].

An average (weighted average) chloroplast numbers in MS-hybrids Roksana and Lenora $\left(\mathrm{A}_{0}\right)$ were about the same $(12.79 \pm 0.35$ and $13.12 \pm 0.42$, respectively). In Iris MS-hybrid the cells were larger and comprised about 15 chloroplasts $(14.92 \pm 0.53)$ which was significantly higher compared to other hybrids (the $t$-criterion of 2.87 и 2.69 , respectively; $\mathrm{P}>0.95)$. An average number of plastotypes in the epidermal tissue of all three MS-hybrids $\left(\mathrm{A}_{0}\right)$ was statistically indistinguishable $(7.2 \pm 0.35,6.5 \pm 0.41,7.3 \pm 0.54)$ (Table 1$)$.

In dihaploid offspring $\left(\mathrm{A}_{1}\right)$ the chloroplast and plastotype number in all variants did not change reliably compared to parent MS-hybrids $\left(\mathrm{A}_{0}\right)$ (see Table 1 ). Therefore, apozygotic seed reproduction did not affect this parameters in stomata guard cells of dihaploids.

1. Chloroplast $(\mathrm{Chl})$ and plastotype $(\mathrm{Pt})$ number in the leaf epidermal tissue in diplod $\left(\mathrm{A}_{0}\right)$, dihaploid $\left(\mathrm{A}_{1}\right)$, and haploid $\left(\mathrm{A}_{1}\right)$ plants of three sugar beet (Beta vulgaris L.) male-sterile hybrids

\begin{tabular}{|c|c|c|c|c|c|c|c|c|}
\hline \multirow{2}{*}{ Ploidy } & \multirow{2}{*}{ Progeny } & \multirow{2}{*}{$\begin{array}{l}\text { Plant } \\
\text { number }\end{array}$} & \multicolumn{2}{|c|}{ Chl number } & \multirow{2}{*}{$C V, \% *$} & \multicolumn{2}{|c|}{ Pt number } & \multirow{2}{*}{$\begin{array}{l}D_{\text {average }} \\
\text { (Min-max) }\end{array}$} \\
\hline & & & $M_{\mathrm{W}} \pm m$ & $\min -\max$ & & $\mathrm{Pt} \pm m$ & $\min -\max$ & \\
\hline \multicolumn{9}{|c|}{ Hybrid Roksana } \\
\hline Diploids & $\mathrm{A}_{0}$ & 10 & $12.79 \pm 0.35$ & $11.1-14.9$ & 12.35 & $7.2 \pm 0.35$ & $6-10$ & $1.30(1.18-1.44)$ \\
\hline Dihaploids & $A_{1}$ & 10 & $13.16 \pm 0.41$ & $11.3-15.6$ & 14.69 & $8.2 \pm 0.47$ & $7-10$ & $1.24(1.07-1.47)$ \\
\hline Haploids & $\mathrm{A}_{1}$ & 55 & $\begin{array}{l}12.32 \pm 0.30 \\
\mathrm{H} \mathrm{y} \mathrm{b} \mathrm{r} \mathrm{i} \mathrm{d}\end{array}$ & $\begin{array}{l}10.3-16.0 \\
\text { Le nora }\end{array}$ & 17.43 & $8.8 \pm 0.17$ & $6-12$ & $1.16(1.04-1.37)$ \\
\hline Diploids & $\mathrm{A}_{0}$ & 11 & $13.12 \pm 0.42$ & $10.8-15.4$ & 13.05 & $6.5 \pm 0.41$ & $5-9$ & $1.40(1.19-1.70)$ \\
\hline Dihaploids & $A_{1}$ & 15 & $14.22 \pm 0.41$ & $13.1-15.5$ & 9.50 & $7.2 \pm 0.45$ & $5-10$ & $1.50(1.19-1.69)$ \\
\hline Haploids & $\mathrm{A}_{1}$ & 38 & $11.85 \pm 0.35$ & $9.4-19.2$ & 17.96 & $8.8 \pm 0.31$ & $6-12$ & $1.16(1.03-1.31)$ \\
\hline \multicolumn{9}{|c|}{ Hybrid Iris } \\
\hline Dihaploids & $A_{1}$ & 12 & $\begin{array}{l}14.54 \pm 0.40 \\
14.54 \pm 0.40\end{array}$ & $\begin{array}{l}13.9-1 / .5 \\
12.0-17.1\end{array}$ & $\begin{array}{r}10.09 \\
8.33\end{array}$ & $\begin{array}{l}1.2 \pm 0.34 \\
6.2 \pm 0.33\end{array}$ & $\begin{array}{l}5-9 \\
5-7\end{array}$ & $1.51(1.39-1.70)$ \\
\hline Haploids & $A_{1}$ & 40 & $12.27 \pm 0.31$ & $10.4-18.0$ & 15.69 & $8.7 \pm 0.22$ & $6-12$ & $1.17(1.04-1.46)$ \\
\hline
\end{tabular}

In Lenora and Iris haploids the chloroplast number mean was reliably lower compared to parent plants $\left(\mathrm{A}_{0}\right)$ and dihaploid sibs $\left(\mathrm{A}_{1}\right)$. The Roksana male-sterile hybrid was the only one with no reliable difference in chloroplast number in diploids, dihaploids and haploids (12.79, 13.16 and 12.32, respectively). Haploids also were characterized by higher variation on plastotype number being from 6 to 12 where as in diploids and dihaploids its varied from 5 to 10 . The means of this parameter in haploids in all three hybrids in fact coincided (8.7-8.8) being significantly higher then in diploids (7.2-7.3) or dihaploid Lenora and Iris plants (6.2-7.2). In Roksana plants no significant difference was found between dihaploids and haploids (8.2 and 8.8, respectively).

$\mathrm{D}$ (fractal dimension) is associated with cell epigenomic and epiplastome instability in leaf tissue, so that $\mathrm{D}$ is the parameter of cell population variability on chloroplast number per cell and plastotype number per tissue. D differed significantly in diploids and haploids (see Table 1). The ranges of $\mathrm{D}$ value in diploids (1.30-1.40) and dihaploids (1.24-1.51) overlap. Therefore, a single parthenogenetic reproduction had no expressed effect on the parameter, too. Nevertheless, in haploids D was much lower (1.16-1.17) when compared to diploids and dihaploids. At that, no interference was observed, and $\mathrm{D}$ values were close to those early reported in inbred sugar beet lines [15]. 
2. Distribution of produced sugar beet (Beta vulgaris L.) haploids on genome stability $(\mathrm{D})$ in cell populations in three male-sterile hybrids $\left(\mathrm{A}_{1}\right)$

\begin{tabular}{l|c|c|c|c}
\hline \multirow{2}{*}{ Group } & \multicolumn{3}{c|}{ Hybrid } & \multirow{2}{*}{ Total } \\
\cline { 2 - 4 } & Lenora $\mathrm{A}_{1}$ & Iris $\mathrm{A}_{1}$ & Roksana $\mathrm{A}_{1}$ & \\
\hline $1.01-1.10$ & 13 & 9 & 20 & 42 \\
$1.11-1.20$ & 14 & 21 & 21 & 56 \\
$1.21-1.30$ & 9 & 8 & 8 & 25 \\
$1.31-1.40$ & 1 & 1 & 6 & 2 \\
$1.41-1.50$ & 1 & 1 & - & 133 \\
Total & 38 & 40 & 55 & 2 \\
\hline
\end{tabular}

D distribution in three haploid populations (133 plants) is shown in the Table 2. D mostly varied within 1.11-1.20, and in minor fraction of plants it was higher or the same as in diploids. Comparing $\mathrm{D}$ distribution in three samples of haploids, we calculated $G$ and found it to be 13.6 ( $\mathrm{df}=12 ; 0.50<\mathrm{P}<0.30$ ), thus indicating random distribution for D (Table 3). Thus, the combination is possible which allows comparing $\mathrm{D}$ distribution in the haploids, diploids and dihaploids.

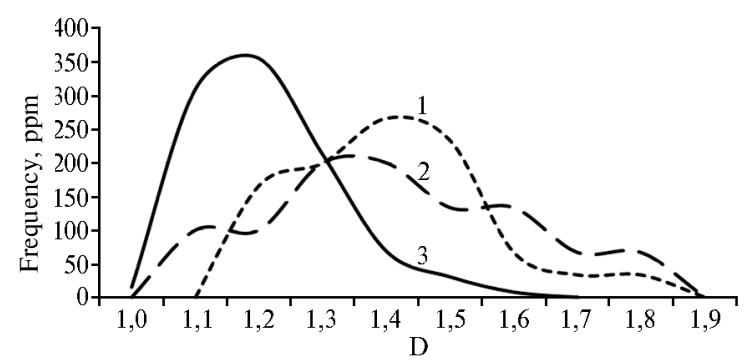

Fig. 3. Distribution of epigenomic stability (D) in diploid (1), dihaploid (2) and haploid (3) sugar beet (Beta vulgaris L.) plants. three haploid samples were identical (1.16-1.17) and differed from corresponding parameter in diploids, though haploids and diploids derived from the same seed progenies (see Table 3).

3. Statistical parameters for cell populations in leaf epidermal tissue in haploid and diploid male-sterile hybrids of sugar beet (Beta vulgaris $\mathrm{L}$.) $\left(\mathrm{A}_{1}\right)$

\begin{tabular}{|c|c|c|c|c|c|c|}
\hline Hybrid & $N$ & $M \pm m$ & $C V, \%$ & $\mathrm{Pt} \pm m$ & $\mathrm{D}$ & $r_{\mathrm{D} / C V}$ \\
\hline \multicolumn{7}{|c|}{ Haploids } \\
\hline Iris & 40 & $12.27 \pm 0.31$ & 15.69 & $8.7 \pm 0.22$ & 1.17 & $-0.77 \pm 0.07$ \\
\hline Lenora & 38 & $11.85 \pm 0.35$ & 17.96 & $8.8 \pm 0.31$ & 1.16 & $-0.87 \pm 0.04$ \\
\hline Roksana & 55 & $12.32 \pm 0.30$ & 17.43 & $8.8 \pm 0.17$ & 1.16 & $-0.86 \pm 0.03$ \\
\hline \multicolumn{7}{|c|}{ Dihaploids } \\
\hline Iris & 12 & $14.54 \pm 0.40$ & 8.33 & $6.2 \pm 0.33$ & 1.51 & -0.50 \\
\hline Lenora & 15 & $14.22 \pm 0.41$ & 9.22 & $7.2 \pm 0.45$ & 1.50 & -0.82 \\
\hline Roksana & 10 & $13.16 \pm 0.41$ & 14.69 & $8.2 \pm 0.47$ & 1.24 & -0.93 \\
\hline
\end{tabular}

N o t e. $N$ is plant number, $M \pm m$ is mean and the error of mean for chloroplast number, $C V$ is coefficient of variation, $\mathrm{Pt} \pm m$ is mean and the error of mean for plastotype number, D is epigenomic stability, $r_{\mathrm{D} / C V}$ is coefficient of liner correlation.

In Table 3 where statistical parameters for haploid and dihaploid plants of three male-sterile hybrids are summarized, $C V$ as index of cell variability on chloroplast number correlated negatively with $\mathrm{D}$ as coefficient of epigenomic stability in cell population with $r$ varying from -0.77 to -0.93 and, thus, approaching -1 in some cases.

Polyploidy is widely spread in plants causing different intra- and interspecial variation [9]. Polyploid series in species of many botanical genera and families are a common example. Different manifestations of individual variation which is widely used in plant breeding are also related with polyploidy [18, 19]. 
Mixoploidy also occurs when in the minor fraction of the cell population the chromosome number is more or less than in the dominant one [5-7, 10].

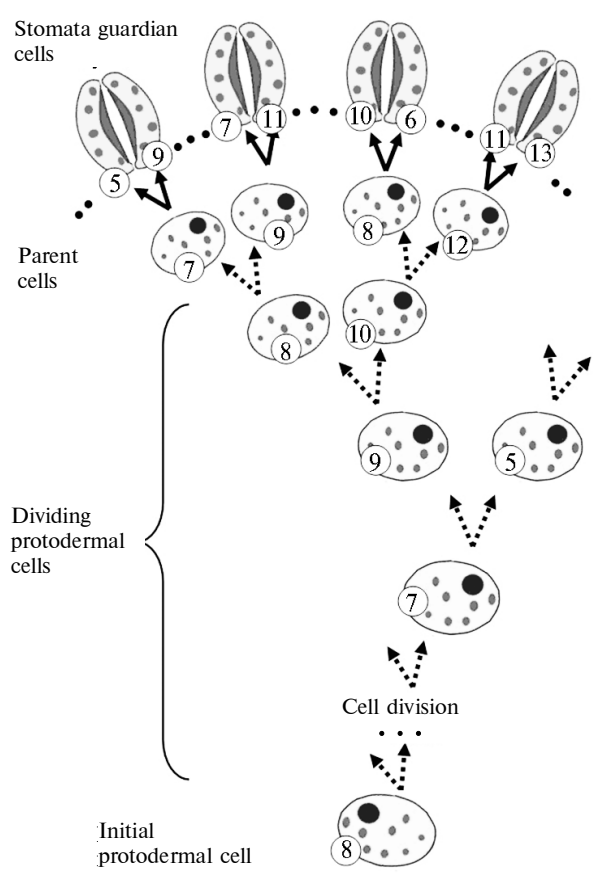

Fig. 4. Scheme of genealogical tree of stomata guardian cell (cyto-fractal) in leaf epidermal tissue (chloroplast number per cell is indicated).

Variation of chloroplast and plasotype number in epidermal tissue is an expression of epigenomic and epiplastom cell instability in ontogenesis. During cell division a protodermal cell becomes parent one and produces two daughter cells which further form guardian cells fixing features of parent protodermal cell such as linear size, ploidy and the number of organelles in cytoplasm [19].

Modeling different biological processes is possible due to fractals [25, 26]. Mathematically, fractal is a set in which Hausdorff-Bazilevich dimension is strictly higher than the topological dimension [18]. In Euclidian geometry, a dimension means the number of spatial coordinates determining location of the point (i.e., one-, two- and threedimensional objects). Fractional number for $\mathrm{D}$ parameter is an attributive feature of any fractals.

Epidermal cells can be considered a tree-like fractal [24]. Plant tissue is a set of cells with the same or different number of organelles. It is like a genealogical tree started from a primordial cell with definite number of plastids. Each cell grows and then divided into two daughter cells. The set of cells in the tissue form geometric structure (Fig. 4), or «plastid fractal» [15]. As genealogical tree is growing (see Fig. 4), the same iteration occurs. A cell divides into two ones with equal or unequal plastid number, and several cell divisions result in appearance of the cell set (tissue) with different chloroplast number. Variation in the cell population is determined by the ploidy and the mode of seed reproduction (i.e., due to fertilization or parthenogenetically) [10].

As it can be seen from Table 1, variation in in chloroplast number in stomata guard cell is associated with epigenimic instability in the cell nuclei in haploids which, in its turn, correlates with homozygosity in self-pollinated progenies. For inbred beet plants, we earlier reported a significant increase in average numbers of organelles in the stomata guard cells [8] and plastotypes in the leaf epidermal tissue [16]. A M:Pt ratio allows us to link the trait of two distinct levels, the tissue level (an average number of chloroplasts per cell) and an individual level (an average number of plastotypes per tissue), so that this ratio is a new geometrical trait peculiar to epidermal tissue of leaf (tissue) as a whole.

Changes in cytological variables of epidermal tissue in inbred sugar beet plants results in decreased fractal D value if inbred and hybrid plants are compared. In other words, higher epigenomic variation (instability) is peculiar to inbred lines compared to hybrids. The epigenome stability was the lowest in the inbred plants and the highest in male-sterile hybrids.

Monogenomic character of cell nucleus in haploids leads to increased cell mixoploidy (endopolyploidy) affecting on the number of chloroplasts $[8,15]$. An increased number of plastotypes in the epidermal tissue of haploids compared 
to dihaploids is the evidence of more unstable genome in haploids. D values in haploid Lenora and Roksana hybrids were the same (1.16), and in haploid Iris plants it was 1.17 . In haploids $D$ values were significantly lower compared to dihaploid sibs $\left(\mathrm{A}_{1}\right)$ and diploid meal-sterile hybrids $\left(\mathrm{A}_{0}\right)$. In all three haploid populations $\mathrm{D}$ values, in fact, were the invariant being significantly different from $\mathrm{D}$ invariants in diploids and dihaploids.

Chloroplast number variation in epidermal cells is related to variability of nuclear size determined by endopoliploidy. High mixoploidy in inbred lines is obviously due to different irregularities in cell divisions leading to an increased level of mixoploidy in somatic cell population and also to variability in the number of organelles (epiplastome variation). Under an infringement in mitosis, both endopoliploid cells (due to chromosome replication without karyokinesis) and endohaploid cells (because of karyokinesis without chromosome replication) can appear in cell populations. In the meristem tissue, triploid and tetraploid cells, and the cells of other ploidy are found along with diploid ones [5-8]. So at cell population level the epigenomic variation occurs due to ploidy determining also epiplastome cell variation.

In our experiments $C V$ values in haploid plants were higher than in dihaploids and diploids. $C V$ is not related directly to activity of distinct genes, gene blocks or external conditions being determined by all intracellular genetic, physiological and biochemical mechanisms. Therefore, the observed variation should be considered epigenetical one, i.e. occurred during plant ontogenesis. Depression is known to be peculiar to homozygous and haploid plants. It is particularly expressed in instability and growth abnormalities compared to hybrids. Such instability is observed under epiplastome variation in sugar beet plants.

$\mathrm{D}$ values found for different beet samples, varied from 1.0 to 1.7 and corresponded to the golden $\rho$-proportion [23], the geometric parameter which describes division of the whole subject to two unequal parts, for instance, the division of a line segment into extreme and mean ratio. A.P. Strakhov suggested a generalized principle of golden ratio according to which the division of a subject as a whole comprises a set of structure invariants, particularly the dichotomic mode of division $(\rho=0)$ and the golden ratio $(\rho=1)$. These D values were observed in our investigation (see Table 3), nevertheless, another values were also reported which corresponded to harmonic proportions occurred at $\rho \geq 2,3,4$, etc. For initial $\rho$ value the harmonious series (structure invariants) are as follows: $1.618,1.465,1.380,1.324,1.285,1.255,1.232$, etc. [26]. D value in hybrids corresponded to the first terms of the harmonious series $(\rho \geq 1,2,3,4)$, while in haploids the $\mathrm{D}$-ratio corresponded to more far terms of the same sequence $(\rho \geq 8,9,10 \ldots)$.

Harmonious proportion and golden ratio are, in fact, invariants which reflect the principle of self-organization in living material. The system, as a whole, can be subjected to changes, however, some its properties remain unchanged.

Thus, found $\mathrm{D}$ ratios in haploid and diploid sugar beet plants make it possible to estimate epigenomic stability and epigenome variation in cell populations. Epigenome and epiplastome variation evaluated as geometrical D parameter characterize physiological state of cell populations in plants during ontogenesis. Heterosis, or hybrid power, is peculiar to one group of plants, the male-sterile hybrids, which possess epigenomic stability with high $\mathrm{D}$ value, while in another group, the haploid plants, a depression with low $\mathrm{D}$ value is characteristic.

\section{R E F E R E N C ES}

1. Joh a n n se n W. The genotype conception of heredity. Int. J. Epidemiol., 2014, 43(4): 989100 (doi: 10.1093/ije/dyu063). 
2. S i s o di y a D., D a s h o r a K., P a n d e y P. Cellular organization and cell reproduction. International J. Adv. Pharm., Biol. Chem., 2012, 1(1): 138-150.

3. M a le t s k i i S.I., R o i k N.V., D r a g a v t s e v V.A. Sel'skokhozyaistvennaya biologiya [Agricultural Biology], 2013, 5: 3-29 (doi: 10.15389/agrobiology.2013.5.3rus, doi: 10.15389/agrobiology.2013.5.3eng).

4. J a blo nka E. Transgenerational epigenetic inheritance: prevalence, mechanisms, and implications for the study of heredity and evolution. The Quarterly Review of Biology, 2009, 84(2): 131-176 (doi: 10.1086/598822).

5. D'A m a to F. Cytogenetics of plant cell and tissue cultures and their regenerantes. CRC Crit. Rev. Plant Sci., 1985, 3(1): 73-112.

6. Ku nakh V.A. V sbornike: Zhebrakovskie chteniya III [In: $3^{\mathrm{d}}$ Zhebrakov's Scientific Meeting]. Minsk, 2011: 53.

7. Maletskii S.I., Kolodyazhnaya Ya.S. Uspekhi sovremennoi biologii, 1999, 119(2): 128-143.

8. B a row M. Endopolyploidy in seed plants. BioEssays, 2006, 28(3): 271-281 (doi: 10.1002/bies.20371).

9. Strakova N., Kocova V., Kolarcik V., Martonfi P. Endopolyploidy in organs of Trifolium pratense L. in different ontogenetic stages. Cariologia, 2014, 67(2): 116-123 (doi: 10.1080/00087114.2014.931632).

10. Yudanova S.S. Miksoploidiya kletochnykh populyatsii sakharnoi svekly $i$ ee svyaz's reproduktivnymi priznakami. Kandidatskaya dissertatsiya [Mixoploidy in sugar beet cell populations as related to reproductive traits. PhD Thesis]. St. Petersburg, 2004.

11. Kolano B., Siwi nska D., Maluszynsk a J. Endopolyploidy patterns during development of Shenopodium quinoa. Acta biologica cracoviensia, Series Botanica, 2009, 51(2): 85-92.

12. Luk as zewska E., S liw inska E. Most organs of sugar-beet (Beta vulgaris L.) plants at the vegetative and reproductive stages of development are polysomatic. Sexual Plant Reproduction, 2007, 20(2): 99-107 (doi: 10.1007/s00497-007-0047-7).

13. Kolano B., S iw inska D., Malus zy nsk a J. Comparative cytogenetic analysis of diploid and hexaploid Chenopodium album Agg. Acta Societatis Botanicorum Poloniae, 2008, 77: 293-298 (doi: 10.5586/asbp.2008.037).

14. B a row M., J ovtch ev G. Endopolyploidy in plants and its analysis by flow cytometry. In: Flow sytometry with plant cells /J. Dolezel, J. Greilhuber, J. Suda (eds.). Wiley-VCH Verlag, Weinheim, 2007: 349-372.

15. Maletski i S.I., Yuda nova S.S., Malets k y a E.I. Vavilovskii zhurnal genetiki $i$ selektsii, 2013, 17(1): 72-80.

16. Maletskaya E.I., Yudanova S.S., Maletski i S.I. Haploids in apozygotic seed progenies of sugar beet (Beta vulgaris L.). Sugar Tech., 2009, 11(1): 61-65.

17. M a lets ki i S.I., M a le t s k a y E.I. Genetika, 1996, 32(12): 1643-1650.

18. Mande l'b rot B. Fraktal'naya geometriya prirody [Fractal geometry in nature]. MoscowIzhevsk, 2010.

19. Yudanova S.S., Ma letskaya E.I., Maletski i S.I. Epiplastome variation of the number of chloroplasts in stomata guard cells of sugar beet (Beta vulgaris L.). Russian J. Genetics, 2004, 40(7): 756-764.

20. G e r m a n a V.A. Gametic embryogenesis and haploid technology as valuable support to plant breeding. Plant Cell Reports, 2011, 30(5): 839-857 (doi: 10.1007/s00299-011-1061-7).

21. S o k a l R.R., Ro hlf F.J. Biometry the principles and practice of statistics in biological research. W.H. Freeman and Company, NY, 1995.

22. M a le t s k i i S.I., Y u d a n o v a S.S. Tsitologiya i genetika, 2007, 41(5): 67-80.

23. St a kh ov A.P. V sbornike: Metafizika. Vek XXI [In: Metaphysics. XXI century]. Moscow, 2006: 174-215.

24. Ufimtsev R. Khvost yashcherki. Metafizika metafory [Lizard tail. Metaphysics of the metaphor]. Kaliningrad, 2010.

25. N u n e z J.A., D e M a r c o R.J. Functional fractals in biology. Biological Theory, 2008, 3(4): 293-296 (doi: 10.1162/biot.2008.3.4.293).

26. Trave rs o S. Cytoskeleton as a fractal percolation cluster: some biological remarks. In: Fractals in biology and medicine. V. 4 /T.F. Nonnenmacher, G.A. Losa, E.R. Weibel (eds.). Birkhäuser Verlag, Basel-Boston-Berlin, 2011. 